\title{
Ebb and Flow When Navigating Adolescence: Predictors of Daily Hassles Among African-American Adolescent Girls
}

\author{
Barbara J. Guthrie, Amy M. Young, Carol J. Boyd, and Eileen K. Kintner
}

ISSUES AND PURPOSE. To examine the nature of

daily hassles as perceived by African-American

adolescent females.

DESIGN AND METHODS. As part of a larger, cross-sectional study, nonrandom network sampling technique was used to survey 178 adolescent girls between the ages of 11 and 19 . RESULTS. This study found that the most common hassles were school and academic, followed by family and economic hassles, peer and social hassles, and personal safety hassles.

Socioeconomic factors were strongly associated with the level of hassles reported.

PRACTICE IMPliCations. Assess AfricanAmerican girls' perception of daily hassles, specifically school-and family-related hassles, and also examine the interrelationship between the type of hassles and health problems.

Search terms: Adolescence, blacks, daily hassles, ethnic groups, females

Accepted for publication October 2, 2001
Barbara J. Guthrie, PhD, RN, is Associate Professor, School of Nursing and Women's Studies; Amy M. Young, PhD, is a research investigator, Substance Abuse Center; Carol J. Boyd, PhD, RN, FAAN, is Professor, School of Nursing, and Director, Substance Abuse Research Center; Eileen K. Kintner, PhD, RN, is Assistant Professor, School of Nursing, University of Michigan, Ann Arbor, MI.

A s early as 1979 , stress was viewed as a serious national health concern because of its influence on mental and physical health and disease for all age groups (National Center for Health Statistics, 1980). In fact, a prominent national health-promotion and disease-prevention objective is to reduce the adverse effects of stress so that less than $35 \%$ of the American population is affected (U.S. Department of Health and Human Services, 2000). Adolescents are no less immune than the rest of the population from the effects of stress. Among adolescents, a consistent relationship has been found between stress and emotional problems (Compas, Orosan, \& Grant, 1993), mental and physical health (Ebata \& Moos, 1994), and problem behavior (Zimmerman, Ramierez-Valles, Zapert, \& Maton, 2000).

Particular subpopulations of adolescents, however, may be particularly vulnerable to the deleterious health effects of stress. African-American teens, particularly African-American teenage girls, are one such subpopulation. While African-American adolescents are privy to the same stresses that accompany all youth in their transition through adolescence, several researchers have found that lower-income African-American adolescents are faced with more stress than their European American counterparts (Comer, 1995). Not only do African-American females appear to be faced with greater amounts of stress than other subgroups, stress-related illnesses such as overeating, depression, anxiety, and cardiovascular disease disproportionately affect African-American females (Williams, 2002). Moreover, one of the studies that examines the health implications of stress among African-American adolescent girls indicates that negative health consequences of stress begin even before 
adulthood. For example, Brown, Powell, and Earls (1989) found that stressful life events were associated with higher rates of depression, conduct disorders, and substance use among African-American girls. This study suggests that stress will have profound health implications for AfricanAmerican girls by adulthood, if not earlier.

\section{African-American girls may experience}

\section{stress as a result of the social status}

\section{associated with being African-American in}

\section{American society.}

Despite the prevalence and health ramifications of stress on the lives of African-American females, the scientific community continues to know little about the nature of stress as perceived by African-American females. Toward the goal of better understanding experiences of stress among African-American adolescent females, this study has two purposes: (a) to describe one-dimensional type and amount of daily hassles commonly reported by African-American adolescent girls from working class backgrounds, and (b) to examine the role of socioeconomic contextual factors, such as perceptions of income, everyday experiences of discrimination, and toughness of neighborhood, in understanding daily hassles in the lives of African-American adolescent girls.

\section{Literature Review}

Adolescence is one of the most challenging and consequential periods during the life course. Common challenges of adolescence include potential stressful life events such as biological changes, environmental transitions, and social changes in relationships with significant others (Petersen, Leffert, Graham, Alwin, \& Ding, 1997).
Some adolescents, however, may be affected by additional stresses above and beyond the strain associated with normative adolescent experiences. African-American adolescents, particularly African-American girls, are one such group that is likely to experience additional strains during adolescence because of their socioeconomic context.

African-American adolescents are more likely than are adolescents of other ethnic groups to grow up in financially impoverished conditions because AfricanAmerican women tend to live in poverty for longer (Willie, Rieker, Kramerk, \& Brown, 1995). Specifically, African-American youth under the age of 18 years are more likely to live below the poverty level (U.S. Bureau of Census, 2000). Poverty is associated with other chronic stressful conditions such as child-care problems, unemployment, inadequate and dangerous living conditions, and, therefore, poverty signifies more than just insufficient income or financial problems. Moreover, many African-American teenage girls are pushed into premature adult-related behaviors because of the economic strain experienced by mothers who are single parents (McLoyd, 1998). Previous research (Boyd-Franklin, 1995) found that African-American adolescent females residing in single female-headed and low-income households might have to carry adult responsibilities such as the care of younger children that often leads to "parental children" (p. 246). As a result, young females may tend to expend an enormous amount of energy carrying out these adult responsibilities, which in turn may have an impact on their attention to normative teen challenges, such as addressing academic and peerrelated concerns.

In addition to the chronic stressful conditions associated with poverty and single-parent households, African-American girls may experience stress as a result of the social status associated with being African-American in American society. Although few if any studies have examined the impact of discrimination on adolescent girls, research on the implications of discrimination on African-American adults suggest it may be a major source of chronic stress. Many African-American adults 
view racial discrimination as a chronic stress that affects their quality of life (Utsey, Ponterotto, Reynolds, \& Cancelli, 2000). This daily experience has been linked to the onset of several stress-related diseases such as high blood pressure, hypertension, stroke, and cardiovascular disease (Krieger \& Sidney, 1996). Consequently, the stress associated with the perception of everyday experience of discrimination ranks high on the list of stress-related problems African-American adults encounter (Broman, Mavaddat, \& Hsu, 2000) and is a likely stress-producing factor for African-American adolescent girls.

\section{Purpose}

Previous literature suggests that stress may have profound implications on the physical and psychological health of African-American females, yet little is known about how this population experiences stress. The purpose of this descriptive study, therefore, was to explore the nature of stress as perceived by African-American adolescent girls from working- and lower-class backgrounds.

Stress associated with daily hassles rather than stress associated with life events was examined in this study. Daily hassles - the irritating, frustrating, and distressing demands that to some degree characterize everyday transactions with the environment - may represent a better conceptualization of stress than traditional life events (Lazarus \& Folkman, 1984). Research on stress (Seidman et al., 1998) indicates that the influence of stresses such as major negative life events on child and adolescent development is often mediated through the more proximal influence of daily hassles. Further, daily hassles are more likely to capture and assess the daily ebb and flow unrelated to stress that emerges from the interaction between individuals and their environment (Hahn \& Smith, 1999) and, therefore, may be able to better capture the effects of the socioeconomic context on the lives of African-American girls.

The first objective of this study was to describe the type and the quantity of daily hassles reported by AfricanAmerican adolescent girls from working-class backgrounds. The second objective was to examine the role of socioeconomic factors in understanding African-American girls' experiences of daily hassles. Based on previous literature that documents the numerous irritations and frustrations commonly faced in underserved communities of color, we hypothesized that three socioeconomic factors (low income, experiences of discrimination, toughness of neighborhood) would positively predict the number of hassles reported. Further, we explored the relationships among these three socioeconomic factors and different types of daily hassles, such as academic, social, family, and personal safety. Because previous research has not examined predictors of different types of hassles, prior predictions regarding the relationships among particular types of hassles and socioeconomic factors were not made.

\section{Methods}

\section{Sample}

This study is part of a larger cross-sectional, research project, "Female Adolescent Substance Experience Study" (F.A.S.E.S.), funded by the National Institute of Drug Abuse and collected from 1996 to 1997 (Guthrie, 1995). A nonrandom network sampling technique, which consists of asking all potential respondents to provide a list of friends or acquaintances who they thought might be interested in participating in the project was used. In order to participate in the parent study, the girls had to be younger than 19 years of age, have no living children, and not have been married. A total of 500 adolescents girls between the ages of 11 and 19 years were recruited into the parent study. Specifically, all participants were recruited using fliers and posters that were placed in various community-based agencies. During the initial screening, the research staff would ask the teen for permission to call her legal guardian or parent in order to obtain initial consent. The participant was informed that in order for her to participate, parental consent and her assent were necessary. Once written assent and consent were obtained, face-to-face interviews were conducted that lasted approximately an hour and a half. Selected data from these interviews are 


\section{Ebb and Flow When Navigating Adolescence: Predictors of Daily Hassles Among African-}

American Adolescent Girls

included in this study. Human subject approval was obtained through a university's Internal Review Board prior to data collection.

Only those participants of the sample who described themselves as having an African-American ethnic background and who were not pregnant $(N=105)$ were included in the secondary analyses reported here. (Thirty pregnant African-American girls were not included in the analyses because of the likelihood that their experiences of stress were dramatically different from the nonpregnant African-American girls included in the study.) The age of this subsample ranged from 11 to 19 years and averaged $15.45(S D=1.80)$, primarily lived in female-headed families, and perceived themselves as middle class. It should

\section{Table 1. Demographic Characteristics}

\section{Characteristics}

Age $(N=105)$

- 11-13

- $14-15$

- $16-17$

- $18-19$

Primary means of support $(N=105)$

- Parents

- Other relatives or boyfriend

- Self

- Public assistance

Dependent on someone receiving public assistance $(N=105)$

- Yes

- No
Perceived social class $(N=105)$

- Lower

- Middle

- Upper

- Other

7.6
70.5
18.1
3.8

be noted, however, that $37.1 \%$ of this subsample $(n=39)$ reported receiving some form of public assistance, suggesting that a greater number of participants' actual class level was lower than how they perceived themselves. Table 1 summarizes demographic data for the subsample included in the analyses reported here.

\section{Instruments}

Data for the F.A.S.E.S. study were collected with a paper-and-pencil, self-report, Likert-type questionnaire and included measures pertaining to physical and psychological health, substance use, sexual activity, self-perceptions, ethnic identity, familial and peer relationships,

\section{Characteristics}

Perceived income comparison $(N=105)$

- More money than other teens their age

- Same amount of money as other teens their age $\quad 65.4$

- Less money than other teens their age

Religious preference $(N=105)$

- Protestant

- Catholic

- Other

- No preference

Number of places lived in the last year $(N=101)$

- Lived in the same place

- Moved once

- Moved more than once

Mother figure in home $(N=105)$

- Yes

- No

Father figure in home $(N=105)$

- Yes

- No 
and perception of neighborhood. In addition to the Likert-type questions, several open-ended questions were included. Details of the measures used in the analyses are reported here.

Daily hassles. The number of daily hassles was measured with the Daily Hassles for Adolescents Scale (Dubois, Felner, \& Meares, 1994; Rowlison \& Felner, 1988), a 26-item self-report inventory of day-to-day concerns of children and adolescents (e.g., fights with brothers or sisters, conflicts with teachers). Respondents are asked to rate on a 4 -point scale ( $1=$ not at all a hassle, $4=$ a very big hassle) the extent to which each item was a hassle during the past week. The scale provides a cumulative index of the overall number of daily life hassles, as well as a count of the number of hassles that pertain to four distinct domains within the adolescent's life-academic/school (e.g., "trying to get good grades"), so$\mathrm{cial} /$ peer (e.g., "not being part of the popular group"), family/economic (e.g., "having to take care of younger brothers/sisters"), and personal safety/health (e.g., "getting beaten up"). Previous studies have demonstrated that the Daily Hassles for Adolescents Scale has good construct validity. Only the cumulative hassle index, created by summing all items, was used in this study. The internal consistency for this cumulative score was .82 (Dubois et al.; Rowlison \& Felner).

Perception of discrimination. Routine and relatively minor experiences of unfair treatment were measured with the Everyday Discrimination Scale. The stem of the scale asks participants "In your day-to-day life how often have any of the following things happened to you?" There are eight response items that capture the frequency of the following experiences in day-to-day lives of participants (Williams, Yu, Jackson, \& Anderson, 1997):

- Being treated with less courtesy than others

- Being treated with less respect than others

- Receiving poorer service than others in restaurants or stores

- People acting as if you are not smart

- Others feeling they are better than you

- They think you are dishonest
- Being called names or insulted

- Being threatened or harassed

Williams et al. (1997) have reported high internal consistency (alpha $=.88$ ) for the scale; however, for this sample the Cronbach alpha was .73.

Toughness of neighborhood. The neighborhood context was measured using The Perception of Neighborhood Scale (Dembo, Schmeidler, Burgos, \& Taylor, 1985), a 20-item scale that measures adolescents' perception of the neighborhood and various images of people within the neighborhood. The Perception of Neighborhood Scale has two subscales: (a) 13 items that measure the adolescent's view of the degree of toughness of the neighborhood; and (b) 7 items that describe images of persons (e.g., junkie, good student, pregnant teen, good athlete). Response scores range from 1 (strongly agree) to 5 (strongly disagree), with a high score indicating a very tough neighborhood and very tough images. Only the first subscale measuring the toughness of neighborhood was used in this study. Previous studies have reported a Cronbach alpha of .90 for the toughness of neighborhood subscale (Dembo et al.); however, for this sample the Cronbach alpha was .81 .

Income. Subjective perception of income was assessed by a single question that asked participants "In what social class do you consider yourself to be: lower, middle, upper, or other?" This measure of perception of income was based on the argument by Krieger, Williams, and Moss (1997) that traditional measures for measuring socioeconomic status often fall short of yielding useable and explainable results because they fail to take into account the subjective assessment of status. Krieger, therefore, has suggested an alternative method of assessment that includes having individuals living within the same community compare themselves against each other at the community, family, and individual level. In addition, researchers (Krieger et al.) found that adolescents' knowledge of traditional indicators for measuring Social Economic Status (e.g., family income, parent's education level) tend to be unreliable and inconsistent. 


\section{Ebb and Flow When Navigating Adolescence: Predictors of Daily Hassles Among African-}

American Adolescent Girls

\section{Data Analysis}

Univariate analyses were first conducted on the overall hassle scale, the four subscales (school/academic, peer/social, family/economic, personal safety), and the individual items in order to provide descriptive information regarding the girls' perceptions of daily hassles. Preliminary bivariate analyses were conducted prior to hypothesis testing. Next, bivariate correlations were conducted among all the socioeconomic variables, hassle subscales, and overall hassle scale. Finally, to test the hypotheses, multiple regression analyses were conducted using the three socioeconomic variables as predictors and the hassles subscales and overall scales as dependent variables (five regression equations in total). Moreover, the bivariate analyses indicate that the predictor variables were not correlated strongly enough to create multicollinearity in the multiple regression equations.

\section{Results}

Table 2 presents descriptive data regarding the girls' perceptions of daily hassles. As is evident, 10 of the 15 most commonly reported hassles pertained to the school/academic domain, suggesting that the participants are particularly focused on and troubled by the academic arena. Likewise, the standardized means (mean/maximum score) of the hassle subscales were calculated so that the four hassle variables had comparable scaling. The standardized means indicated the types of hassles most commonly reported by the participants were school/academic (.46), followed by peer/social (.13), family/economic (.29), and personal safety (.08).

Bivariate correlations among the socioeconomic variables and the hassles scales are presented in Table 3 . As expected, the correlations among the hassle subscales are all positive and large. Contrary to expectation, however, the correlations among the socioeconomic variables were not significant. As the correlations between the hassle scales and the socioeconomic variables were generally large and in the expected direction, these bivariate analyses were fol-
Table 2. Fifteen Most Commonly Reported Daily Hassles $(N=105)$

\section{Hassle}

Trying to get good grades Doing household chores

Parental pressure to do well Not getting along with teachers

Having a hard teacher

Not understanding class work

Keeping up with school work

Conflict with other students

Possibly failing a course

Being bored at school

Not having enough money

Teachers expecting too much

Problems with acne/weight/height

Getting bad grades

Conflict with parents about leisure time

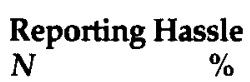

$\begin{array}{ll}93 & 88.6 \\ 83 & 79.0 \\ 71 & 67.6 \\ 68 & 64.8 \\ 66 & 62.9 \\ 66 & 62.9 \\ 63 & 60.0 \\ 58 & 55.2 \\ 58 & 55.2 \\ 58 & 55.2 \\ 58 & 55.2 \\ 54 & 51.4 \\ 53 & 50.5 \\ 52 & 49.5 \\ 45 & 42.9\end{array}$

lowed with multiple regression analyses to test the hypotheses.

Standard multiple regression tests analyzing the relationship between socioeconomic variables and the hassles scales revealed that all three socioeconomic variables were significantly related to the overall hassles scale when controlling for the two other socioeconomic variables $\left(R^{2}=\right.$ $.26, F=11.72, p<.001)$. The strongest relationship was between perceptions of discrimination and hassles $(\beta=.40$, $t=4.62, p<.001$ ), followed by toughness of neighborhood $(\beta=.20, t=2.35, p<.05)$, and income $(\beta=-.18, t=$ $-2.10, p<.05)$.

Exploratory analyses also were conducted to determine whether the socioeconomic variables were particularly relevant to specific types of hassles. Perception of discrimination had a strong positive relationship to aca$\mathrm{demic} / \mathrm{school}$ hassles $(\beta=.40, t=4.48, p<.001)$, while neither income nor toughness of neighborhood were related to academic/school hassles $\left(R^{2}=.20, F=8.37, p<.001\right)$. All three socioeconomic variables were significantly related to peer $/$ social hassles $\left(R^{2}=.22, F=9.6, p<.001\right)$, with per- 
Table 3. Bivariate Correlations Among Hassle Scales and Socioeconomic Variables $(N=105)$

\begin{tabular}{|c|c|c|c|c|c|c|c|c|c|c|c|c|}
\hline & $\begin{array}{c}\text { Total } \\
\text { Hassles }\end{array}$ & S/A & $\mathbf{P} / \mathbf{S}$ & F/E & PS & I & D & $\mathrm{TN}$ & QF & $\mathbf{R M}$ & RF & DV \\
\hline Total hassles & 1.00 & $.78^{c}$ & $.70^{c}$ & $.78^{c}$ & $.56^{c}$ & $-.20^{\mathrm{a}}$ & $.42^{\mathrm{c}}$ & $.26^{\mathrm{a}}$ & $-.29 b$ & $-.23^{a}$ & -.13 & $.21^{\mathrm{a}}$ \\
\hline School/academic (S/A) & $.78^{c}$ & 1.00 & $.41^{\mathrm{c}}$ & $.73^{c}$ & $.33^{b}$ & -.08 & $.42^{c}$ & .18 & $-.24^{\mathrm{a}}$ & -.18 & -.06 & .16 \\
\hline Peer/social (P/S) & $.70^{c}$ & $.41^{\mathrm{c}}$ & 1.00 & $.42^{\mathrm{c}}$ & $.37 c$ & $-.27 \mathrm{~b}$ & $.36^{c}$ & $.22^{\mathrm{a}}$ & $-.24^{\mathrm{a}}$ & $-.20^{\mathrm{a}}$ & -.02 & .15 \\
\hline Family/economic (F/E) & $.78^{c}$ & $.73^{c}$ & $.42^{\mathrm{c}}$ & 1.00 & $.31^{\mathrm{b}}$ & $-.23^{a}$ & $.31^{\mathrm{b}}$ & .12 & $-.25^{\mathrm{a}}$ & $-.26^{\mathrm{b}}$ & -.15 & $.20^{\mathrm{a}}$ \\
\hline Personal safety (PS) & $.56^{c}$ & $.33^{b}$ & $.37 c$ & $.31^{\mathrm{b}}$ & 1.00 & -.12 & .14 & $.23^{\mathrm{a}}$ & -.18 & -.00 & -.04 & .10 \\
\hline Income (I) & $-.20^{\mathrm{a}}$ & -.08 & $-.27 \mathrm{~b}$ & $-.23^{\mathrm{a}}$ & -.12 & 1.00 & -.03 & -.02 & $.23^{a}$ & $.35^{c}$ & .12 & .04 \\
\hline Discrimination (D) & $.42^{c}$ & $.42^{c}$ & $.36^{c}$ & $.31^{\mathrm{b}}$ & .14 & -.03 & 1.00 & .11 & $-.28^{\mathrm{b}}$ & $-.26^{\mathrm{a}}$ & -.12 & .18 \\
\hline Toughness of neighborhood (TN) & $.26^{\mathrm{b}}$ & .18 & $.22^{\mathrm{a}}$ & .12 & $.23^{\mathrm{a}}$ & -.02 & .11 & 1.00 & $-.27 \mathrm{~b}$ & -.16 & .03 & .02 \\
\hline Quality of family relations (QF) & $-.30^{\mathrm{b}}$ & $-.24^{\mathrm{b}}$ & $-.24^{\mathrm{a}}$ & $-.25^{\mathrm{a}}$ & -.18 & $.23^{\mathrm{a}}$ & $-.28^{\mathrm{b}}$ & $-.27 \mathrm{~b}$ & 1.00 & $.56^{\mathrm{c}}$ & $.38^{c}$ & -.03 \\
\hline Quality of relationship with mother (RM) & $-.23^{a}$ & -.18 & $-.20^{\mathrm{a}}$ & $-.26^{\mathrm{b}}$ & -.004 & $.35^{\mathrm{c}}$ & $-.26^{\mathrm{b}}$ & -.16 & $.56^{\mathrm{c}}$ & 1.00 & $.37 \mathrm{c}$ & -.02 \\
\hline uality of relationship with father (RF) & -.13 & -.06 & -.02 & -.15 & -.04 & .12 & -.12 & .03 & $.38^{c}$ & $.37 \mathrm{c}$ & 1.00 & .08 \\
\hline Dating violence (DV) & $.21^{\mathrm{a}}$ & .18 & .15 & $.20^{\mathrm{a}}$ & .10 & .04 & .18 & .02 & -.03 & -.02 & .08 & 1.00 \\
\hline
\end{tabular}

a $p<.05$, b $p<.01, c p<.001$

ceptions of discrimination most strongly related $(\beta=.32$, $t=3.67, p<.001)$, followed by income $(\beta=-.26, t=-2.90$, $p<.01)$ and toughness of neighborhood $(\beta=.18, t=2.02$, $p<.05)$. Concerning family/economic hassles, income $(\beta=-.22, t=-2.42, p<.05)$ and perception of discrimination $(\beta=.30, t=3.25, p<.05)$ were significant predictors, whereas toughness of neighborhood was not $\left(R^{2}=.16\right.$, $F=6.18, p<.001$ ). Finally, toughness of neighborhood was the only significant predictor of personal safety hassles $(\beta=.20, t=2.10, p<.05)\left(R^{2}=.08, F=2.88, p<.05\right)$.

\section{Discussion}

Descriptive analyses of the data indicate the most common hassles were school and academic irritants (e.g., "not getting along with the teacher," "having a hard teacher"), followed by family and economic hassles (e.g." "too many people relying on you at home," "not having a good place to do school work at home,"), peer and social hassles (e.g., "having trouble making friends," "not being part of popular group"), and personal safety hassles ("being pressured to drink and smoke," "getting beaten up").

Several studies have found that African-American adolescents often experience school-related tension or stress due to a number of factors such as lack of parental education (McLoyd, 1998), negative parental attitude (McLoyd), incompatibility among the adolescents' backgrounds or home cultures and school expectations, ethnic norms and school norms, and social class differences (Comer, 1995). Robinson and Ward (1991) suggest that 


\section{Ebb and Flow When Navigating Adolescence: Predictors of Daily Hassles Among African-}

American Adolescent Girls

African-American girls' school-related hassles tend to arise when these girls fail to conform to dominant perspectives of how girls should speak and behave. Specifically, they found that African-American girls who are viewed by their teachers as outspoken, strong, and tough report more school-related irritation. Hare (1985) provides another plausible explanation. He found that when African Americans' domain-specific self-esteem (i.e., home, school, and peers) is assessed, the most consistent domain in which African Americans tend to have lower self-esteem is at school. Thus, it may be that if AfricanAmerican girls feel poorly about themselves while in school, they are more likely to perceive school as a hassle.

The findings suggest that feelings of

\section{isolation and not belonging are congruent}

with the idea that African-American girls'

$$
\text { perception of self is "we." }
$$

Our study also found that the broad socioeconomic context in which these girls were situated played an important role in the type and amount of stress they experienced. All three of the socioeconomic variables examined in the study (income, perception of discrimination, toughness of neighborhood) were significantly related to hassles in general for African-American adolescent girls from working-class backgrounds. Our study also indicates, however, that socioeconomic factors were particularly salient for some types of hassles (e.g., social) but not others. Most noteworthy is our finding that discrimination was a strong predictor of school-related hassles, whereas income and toughness of neighborhood did not predict school-related hassles, suggesting that girls who report school-related hassles (e.g., "teachers expect too much") feel discriminated against but do not necessarily perceive having less income than their peers or perceive their neighborhoods to be particularly tough.

In contrast, all three socioeconomic factors were significant predictors of peer-related hassles, indicating that girls who reported social hassles (e.g., "not being part of the popular group") perceived they were discriminated against, had lower incomes than their peers, and lived in particularly tough neighborhoods. The findings suggest that feelings of isolation and not belonging are congruent with the idea that African-American girls' perception of self is "we." And when they don't experience a sense of "we," they tend to feel more isolated, which in turn may lead to a sense of daily stress related to peers (Collins, 1990).

As would be expected, we found that income was a significant predictor of family and economic hassles (e.g., "not having a good place to do school work at home"). We also found, however, that perceived discrimination was a significant predictor of family and economic hassles. McLoyd (1998) found that economic hardship exposes adolescents to more acute and chronic stress, which in turn weakens their ability to cope. Similarly, these same youth are likely to have adult responsibilities thrust on them, such as cooking, cleaning, and caring for their younger siblings. Moreover, McLoyd found that mothers of girls living in economic hardship tended to share the family's financial problems more with their daughters than with their sons, thus superimposing emotional precocity that exceeds their chronological age.

Regarding the significant relationship between perceived day-to-day discrimination and family and economic hassles, several scholars have provided theoretical and empirical linkage substantiation. Stress generally, and particularly race-related stress, is integrally linked to social structure and social status, and social roles determine both the type and quantities of stress to which an individual is exposed (Pearlin, 1998). Therefore, Williams et al. (1997) posit that because African Americans generally occupy a lower class in society, they are more likely to experience higher levels of stress and, more specifically, everyday race-related stress than their European counterparts. Finally, the only significant predictor of personal safety hassles was perceiving the neighborhood 
as particularly tough, a finding that is expected given the items that compose the personal safety hassle subscale (e.g., "getting beaten up"). Research (Robert, 1998) has found that individuals living in communities with low socioeconomic levels and high inequality in income distribution tend to report higher levels of perceived crime and perception of being unsafe. Perceptions of crime tend to indirectly affect health by increasing stress, and they promote social isolation and a fear of traveling freely in the community.

The present study has several limitations. First, the findings cannot be generalized beyond the sampled population because the convenience sample was small and nonrandom. In order to substantiate the findings, studies using a population-based sampling are needed. Second, the data were retrospective and cross-sectional, factors that make statements about causality or temporality difficult. According to Turner, Wheaton, and Lloyd (1995), daily hassles provide one profile of stress; however, several other dimensions, such as chronic stress and traumatic life events, should be considered in future studies. Research that explores these relationships has the potential to provide a more comprehensive understanding of the relevance of stress, specifically daily hassles, on the smoking patterns of African-American adolescent girls.

\section{How Do I Apply These Findings to Nursing Practice?}

In spite of the fact that the results cannot be generalized about the population at large, the findings have applicability for nurses promoting health with AfricanAmerican girls. Specifically, nurses need to begin to incorporate into their health assessments questions about daily hassles that pertain to the four distinct domains within the adolescent's life generally, and African-American adolescent girl's life in particular - academic/ school (e.g., "trying to get good grades"), social/peer (e.g., "not being part of the popular group"), family/economic (e.g., "having to take care of younger brothers/sisters"), and personal safety/health (e.g., "getting beaten up").

Nurses not only need to ask about existence of any daily hassles, but also about any changes in level of inten- sity, as well as what they might do to relieve or cope with these hassles. Given that perception of everyday discrimination was significantly related to daily hassles, questions related to perceptions of being treated differently should be included in any health assessment inventory. The experience of daily hassles, coupled with ongoing experiences of being treated differently, may produce short-term responses, which may be manifest as behavioral (e.g., smoking), physiological (e.g., changes in blood pressure), or psychological (e.g., tension headaches) outcomes.

If these responses continue over time, they may lead to long-term negative health outcomes such as hypertension or other cardiovascular diseases (Twisk, Snel, Kempler, \& Van Mechelen, 1999). This study offers a first step toward conceptualizing the developmental trajectory related to when and how daily hassles become chronic stresses for African-American females.

Author contact: bguthrie@umich.edu, with a copy to the Editor: roxie.foster@uchsc.edu

\section{References}

Boyd-Franklin, N. (1995). Therapy with African American inner-city families. In R.H. Mikesell (Ed.), Integrating family therapy: Handbook of family psychology and systems theory (pp. 357-371). Washington, DC: American Psychological Association.

Broman, C.L., Mavaddat, R., \& Hsu, S. (2000). The experience and consequences of perceived racial discrimination: A study of African Americans. Journal of Black Psychology, 26, 165-180.

Brown, L.P., Powell, J., \& Earls, F. (1989). Stressful life events and psychiatric symptoms in Black adolescent females. Journal of Adolescent Research: Special issue: Black Adolescents, 4, 140-141.

Collins, K.S. (1990). Black feminist thought: Knowledge, consciousness, and the politics of empowerment. London: HarperCollins Academic.

Comer, I.P. (1995). Racism and African-American adolescent development. In C.V. Willie, P.P. Rieker, B.M. Kramer, \& B.S. Brown (Eds.), Mental health, racism, and sexism (pp. 151-170). Pittsburgh, PA: University of Pittsburgh Press.

Compas, B., Orosan, P., \& Grant, K. (1993). Adolescent stress and coping: Implications for psychopathology during adolescence. Journal of Adolescence, 16, 331-349. 


\section{Ebb and Flow When Navigating Adolescence: Predictors of Daily Hassles Among African- American Adolescent Girls}

Dembo, R., Schmeidler, J., Burgos, W., \& Taylor, R. (1985). Environmental setting and early drug involvement among inner-city junior high school youths. International Journal of Addictions, 20, 1239-1255.

Dubois, D.L., Felner, R.D., \& Meares, H. (1994). Prospective investigation of the effects of socioeconomic disadvantage, life stress, and social support on early adolescent adjustment. Journal of Abnormal Psychology, 103, 511-22.

Ebata, A.T., \& Moos, R.H. (1994). Personal, situational, and contextual correlates of coping in adolescence. Journal of Research on Adolescence, 4(1), 99-125.

Guthrie, B.J. (1995). A model to predict substance use in pregnant adolescents (FASES) [NIDA Grant, K20-DA000233-01A1]. Ann Arbor, MI: University of Michigan Press.

Hahn, S.E., \& Smith, C.S. (1999). Daily hassles and chronic stressors: Conceptual and measurement issues. Stress Medicine, 15, 89-101.

Hare, B.R. (1985). Stability and change in self penception and achievement among Black adolescents: A longitudinal study. Journal of Black Psychology, 11, 29-42.

Krieger, N., \& Sidney, S. (1996). Racial discrimination and blood pressure: The CARDIA study of young Black and White women and men. American Journal of Public Health, 86, 1370-1378.

Krieger, N., Williams, D.R., \& Moss, N.E. (1997). Measuring social class in U.S. public health research: Concepts, methodologies, and guidelines. Annual Review of Public Health, 18, 341-378.

Lazarus, R.S., \& Folkman, S. (1984). Stress, appraisal and coping. New York: Springer.

McLoyd, V.C. (1998). Socioeconomic disadvantage and child development. American Psychology, 53, 185-204.

National Center for Health Statistics. (1980). Health in the United States: Chartbook. Washington, DC: Author.

Pearlin, L.I. (1998). The sociological study of stress. Journal of Health and Social Behavior, 30, 241-256.

Petersen, A.C., Leffert, N., Graham, B., Alwin, J., \& Ding, S. (1997). Promoting mental health during the transition into adolescence. In J. Schulenberg (Ed.), Health risks and developmental transitions during adolescence (pp. 471-497). New York: Cambridge University Press.

Robert, S.A. (1998). Community-level socioeconomic status effects on adult health. Journal of Health and Social Behavior, 39(1), 18-37.
Robinson, T., \& Ward, J.V. (1991). A belief in self far greater than anyone's disbelief. In C. Gilligan, A. Rogers, \& D. Tolman (Eds.), Cultizating resistance among African American female adolescents in women, girls, and psychotherapy (pp. 87-103). Binghamton, MA: Harrington Park Press.

Rowlison, R.T., \& Felner, R.D. (1988). Major life events, hassles, and adaptation in adolescence: Confounding in the conceptualization and measurement of life stress and adjustment revisited. Journal of Personality and Social Psychology, 55, 432-444.

Seidman, E., Yoshikawa, H., Roberts. A., Chesir-Teran, D., Allen, L. Friedman, J.L., \& Aber, J.L. (1998). Structural and experiential neighborhood contexts, developmental stage, and antisocial behavior among urban adolescents in poverty. Developmental Psychopathology, 10, 259-281.

Turner, R.J., Wheaton, B., \& Lloyd, D.A. (1995). The epidemiology of social stress. American Sociological Review, 60, 104-125.

Twisk, J.W.R., Snel, J., Kempler, H.C.G., \& Van Mechelen, W. (1999). Changes in daily hassles and life events and the relationship with coronary heart disease risk factors: A 2-year longitudinal study in 27-29-year-old males and females. Journal of Psychosomatic Research, $46,229-240$.

U.S. Bureau of Census. (2000). Extended measures of well-being: Selected data from the 1984 survey of income and program participation [Current population reports, Series P-70, No. 26]. Washington, DC: Author.

U.S. Department of Health and Human Services. (2000). Healthy People 2010: Understanding and improving health. Washington, DC: Author.

Utsey, S.O., Ponterotto, J.G., Reynolds, A.L., \& Cancelli, A. (2000). Racial discrimination, coping, life satisfaction, and self-esteem among African Americans. Journal of Counseling and Development, $78(1), 72-80$.

Williams, D.R. (2002). Racial/ethnic variations in women's health: The social embeddedness of health. American Journal of Public Health, 92 , 588-598.

Williams, D.R., Yu, Y., Jackson, J.S., \& Anderson, N.B. (1997). Racial differences in physical and mental health: Socio-economic status, stress and discrimination. Joumal of Health Psychology, 2, 335-351.

Willie, C.V., Rieker, P.P., Kramerk, B.M., \& Brown, B.S. (1995). Mental health, racism, and sexism. Pittsburgh, PA: University of Pittsburgh Press.

Zimmerman, M.A., Ramierez-Valles, J., Zapert, K.M., \& Maton, K.I. (2000). A longitudinal study of stress-buffering effects for urban African-American male adolescent problem behaviors and mental health. Journal of Community Psychology, 28(1), 17-33. 